Int. J. Electrochem. Sci., 13 (2018) $9481-9492$

International Journal of

ELECTROCHEMICAL

SCIENCE

www.electrochemsci.org

\title{
Development of Thiocyanate-Selective Membrane Electrodes by the Sol-Gel Method
}

\author{
Na Gyeom Kwon and Sung Bae Park* \\ Department of Chemistry and Research Institute of Basic Sciences, Inje University, \\ Kimhae 50834, Korea \\ *E-mail: chempsb@inje.ac.kr
}

doi: $10.20964 / 2018.10 .42$

Received: 8 January 2018 / Accepted: 8 August 2018 / Published: 1 September 2018

To prepare thiocyanate-selective chemical sensors, a sol-gel-based matrix was employed as a host membrane for the encapsulation of a sensing material. Tricaprylylmethylammonium thiocyanate (Aliquat336-SCN) was used as the dissociated ion-exchanger type sensing ionophore. Both 3isocyanatopropyl-triethoxysilane and 1,4-butanediol were used for appropriate precursor preparation. Under acidic conditions, the sol precursor slowly gelled to yield a film in which the thiocyanate ionophore, Aliquat336-SCN, was encapsulated. Electrochemical responses of the potentiometric sensors were compared to those of traditional poly(vinyl chloride) (PVC) membrane electrodes prepared using the same ionophore. On the $7^{\text {th }}$ working day, the average response slope toward thiocyanate was approximately $56.3 \mathrm{mV} \mathrm{decade}^{-1}$ in the concentration range $10^{-4.5} \mathrm{M}$ to $5 \times 10^{-1} \mathrm{M}$ at $20^{\circ} \mathrm{C}$. Selectivity toward thiocyanate over lipophilic anions such as perchlorate and salicylate was considerably improved. The results exhibit a clear tendency that deviates from the Hofmeister selectivity pattern which would be observed in a membrane electrode made of Aliquat336-SCN type salt. The potentiometric selectivity coefficients, as measured in a $0.05 \mathrm{M}$ 2-morpholinoethanesulfonic acid monohydrate buffer, $\mathrm{pH} 5.5$, were $\log \mathrm{k}^{\mathrm{pot}}$ thiocyanate, chloride $=-2.3, \log \mathrm{k}_{\text {thiocyanate, salicylate }}^{\text {pot }}=-0.6$, and $\log \mathrm{k}^{\text {pot }}$ thiocyanate, perchlorate $=-0.1$. The optimized membrane sensors were employed for the flowinjection measurement of thiocyanate levels in saliva samples from both smokers and nonsmokers. The membrane sensors exhibited a fairly good correlation with the traditional colorimetric method $(\mathrm{n}=23$; sensors $=0.84$ (colorimetric) $\left.+0.13: \mathrm{R}^{2}=0.97\right)$.

Keywords: Thiocyanate-selective electrode, Aliquat336-SCN, Sol-gel encapsulation, Saliva

\section{$\underline{\text { FULL TEXT }}$}

(C) 2018 The Authors. Published by ESG (www.electrochemsci.org). This article is an open access article distributed under the terms and conditions of the Creative Commons Attribution license (http://creativecommons.org/licenses/by/4.0/). 